
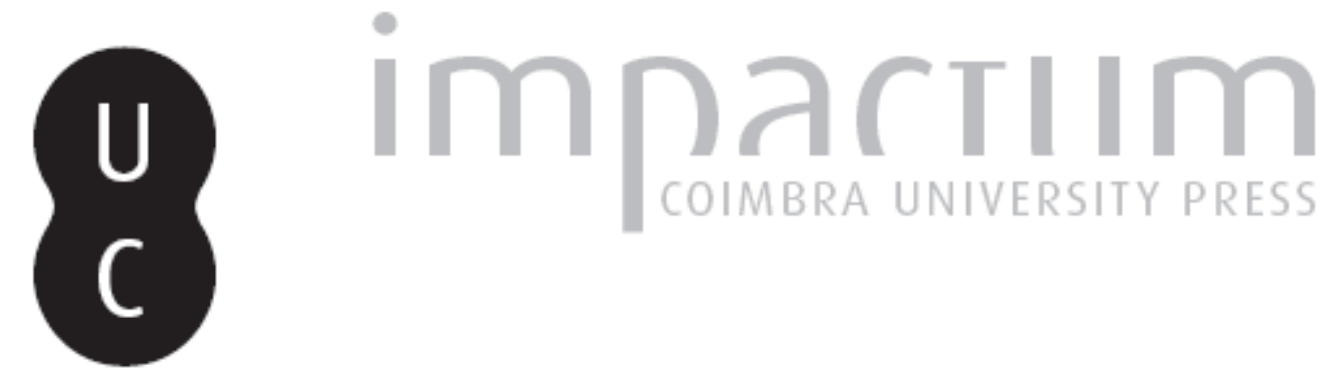

\title{
Estratégias para a diversidade na televisão: os casos dos EUA e do Reino Unido
}

Autor(es): Lourenço, Raquel

Publicado por: Imprensa da Universidade de Coimbra

URL persistente: URI:http://hdl.handle.net/10316.2/43228

DOI: DOI:https://doi.org/10.14195/2183-5462_31_6

Accessed : $\quad$ 26-Apr-2023 16:14:13

A navegação consulta e descarregamento dos títulos inseridos nas Bibliotecas Digitais UC Digitalis, UC Pombalina e UC Impactum, pressupõem a aceitação plena e sem reservas dos Termos e Condições de Uso destas Bibliotecas Digitais, disponíveis em https://digitalis.uc.pt/pt-pt/termos.

Conforme exposto nos referidos Termos e Condições de Uso, o descarregamento de títulos de acesso restrito requer uma licença válida de autorização devendo o utilizador aceder ao(s) documento(s) a partir de um endereço de IP da instituição detentora da supramencionada licença.

Ao utilizador é apenas permitido o descarregamento para uso pessoal, pelo que o emprego do(s) título(s) descarregado(s) para outro fim, designadamente comercial, carece de autorização do respetivo autor ou editor da obra.

Na medida em que todas as obras da UC Digitalis se encontram protegidas pelo Código do Direito de Autor e Direitos Conexos e demais legislação aplicável, toda a cópia, parcial ou total, deste documento, nos casos em que é legalmente admitida, deverá conter ou fazer-se acompanhar por este aviso.

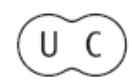




\section{Media Jornalismo}

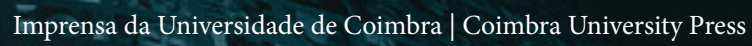

N. 31 Vol. 17, N. ${ }^{\circ} 2$ - 2017

Esia

(2) M MEDIA E DIVERSIDADE

लिखिएक

2)

*).

() (6) $3(9)$

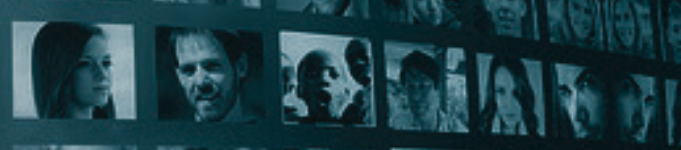

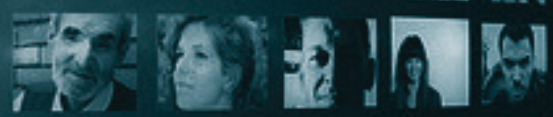

* a

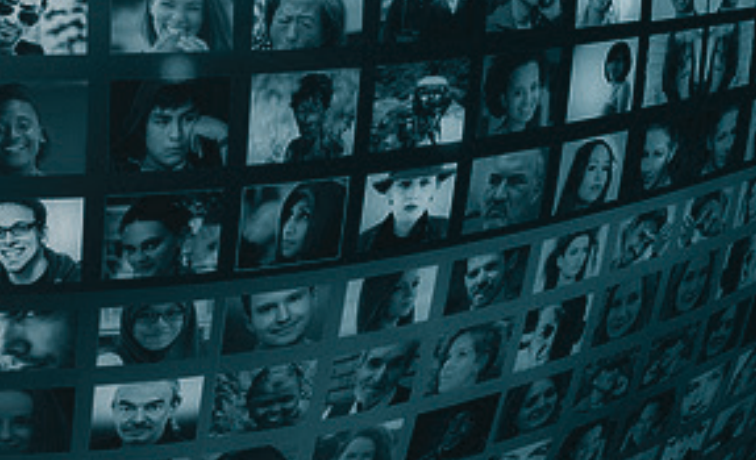

तथ 


\title{
ESTRATÉGIAS PARA A DIVERSIDADE NA TELEVISÃO: OS CASOS DOS EUA E DO REINO UNIDO
}

\author{
STRATEGIES FOR DIVERSITY ON TELEVISION: \\ THE CASES OF US AND UK
}

RAQUEL LOURENÇO

Centro de Investigação em Comunicação, Informação e Cultura Digital

(CIC. Digital FCSH/NOVA), 1069-061 Lisboa, Portugal

raquelfcsh@hotmail.com

\begin{abstract}
Resumo
Neste artigo iremos expor, em síntese, as conclusões de vários estudos sobre a diversidade existente na televisão dos EUA e do Reino Unido. Começamos por explicar o conceito de diversidade nos vários estudos, assim como a importância do tema e o enquadramento legal dos dois países. Em seguida, analisamos o panorama atual ao nível da diversidade, os objetivos a atingir pelas estações de televisão e as várias estratégias propostas pelos investigadores para que seja dada voz às comunidades a que estas se destinam, nomeadamente através da inclusão quer de minorias, quer de mulheres, no conteúdo, no emprego ou na propriedade. Todos os estudos considerados apontam para a necessidade de várias alterações para se conseguir uma diversidade, dentro e fora do ecrã, que seja proporcional à distribuição da população dos dois países.
\end{abstract}

Palavras-chave:

Televisão; diversidade; EUA; Reino Unido; minorias; igualdade

Abstract

In this article, we will expose, shortly, the conclusions of several studies about the diversity existent on television in the US and in the United Kingdom. We start with the explanation of the concept of diversity considered in each study, followed by the importance of this issue and the legal framework in both countries. Then, we will analyse the current landscape regarding diversity, the goals TV stations must achieve and the several strategies proposed by researchers so that voice is given to the communities the TV stations are intended, namely through the inclusion of either minorities and women, in the content, employment or ownership. All the studies taken into account point to the need of making many changes in order to get diversity, inside and outside the screen, proportional to the distribution of the population on these countries.

KEYWORDS:

Television; diversity; US; United Kingdom; minorities; equality 
INTRODUÇÃo

É inegável que os meios de comunicação social desempenham um papel muito relevante para que os cidadãos decidam a importância que dão aos temas presentes na discussão pública, contribuindo também para a visão que os espetadores têm do mundo em geral e das pessoas que os rodeiam. A televisão, em países desenvolvidos, é especialmente relevante porque é o media que apresenta um acesso mais massificado, estando presente na vida de cidadãos de todas as idades, classes sociais, etnias, etc. Assim sendo, torna-se importante verificar se os diferentes cidadãos de um país se sentem bem representados no ecrã e o que é possível fazer para inverter tendências de sub-representação, já que estas constituem um obstáculo para a democracia.

Nos EUA, a FCC (Federal Communications Commission) é o órgão responsável por regular a área das telecomunicações e radiodifusão. Todavia, a Leadership Conference Education Fund, uma organização que luta pela defesa dos direitos humanos e civis dos americanos, mostra-se preocupada com a atuação da FCC em matéria de diversidade, acusando a entidade de aprovar medidas que prejudicam a representação dos cidadãos nos media. No mesmo sentido, investigadores e estudantes da USC's Annenberg School for Communication and Journalism, em Los Angeles, verificam que existe uma falta de representação, nomeadamente de muIheres e indivíduos de raça negra, em programas de entretenimento. É de realçar, ainda, o contributo da GLAAD (Gay \& Lesbian Alliance Against Defamation) que enfatiza a importância de não apenas reverter a sub-representação de homossexuais (femininos e masculinos), transsexuais, bissexuais e pessoas que rejeitam definições tradicionais de género e sexualidade (queer), mas também de dotar estas personagens de complexidade e profundidade, assim como de maior protagonismo nas histórias, já que consideram exagerado o número de personagens, incluídas nestas categorias, que morrem antes do final das séries e filmes.

Relativamente ao Reino Unido, é a própria estação pública (BBC) a reconhecer que a diversidade que apresenta, quer ao nível de trabalhadores, quer de presença visível no ecrã, está aquém do necessário para garantir igualdade de oportunidades e representação para todos os britânicos, pelo que apresenta um conjunto de estratégias para reverter a situação até 2020. Também o Ofcom (Office of Communications), entidade responsável por regular as comunicações no país, procura dar indicações, nomeadamente orientação jurídica, aos empregadores e proprietários dos media, para que sejam tomadas medidas de promoção da diversidade, mantendo o respeito pela lei.

\section{DIVERSIDADE: CONCEITO E IMPORTÂNCIA}

A BBC assume-se como uma organização "diversa e inclusiva", onde a diversidade é uma questão "natural", inerente ao seu processo criativo e à sua cultura. A afirmação está presente no relatório "Diversity and Inclusion Strategy2016-2020", cujo subtítulo é "Diversity includes everyone". Para a emissora, o conceito de diversidade inclui "todas as diferenças existentes entre as pessoas". Estão incluídas questões visíveis como o sexo, a raça, a etnia e deficiências notórias, mas também diferenças não-visíveis como a orientação sexual, a classe social, a herança cultural, a religião, deficiências não notórias, diferentes perspetivas e formas de pensar, 
educação, estatuto social da família e idade. Todavia, a BBC inclui, ainda, neste conceito, as nações e regiões nas quais tanto as audiências, como os funcionários, vivem e trabalham. A ideia de inclusão, contida nesta definição, significa, então, "valorizar e celebrar diferenças, encorajando a existência de um local de trabalho onde a cultura permita uma boa convivência, para que todos os indivíduos sejam apoiados, respeitados e envolvidos, tenham uma voz e sejam capazes de desenvolver capacidades e talentos, em linha com os valores da BBC" (BBC, 2016: 5).

Também a Leadership Conference Education Fund define o conceito de diversidade nos media, num relatório intitulado "Media Diversity Matters: A Media Justice Activist Toolkit". Media diversos são, assim, "aqueles que incluem minorias e mulheres no conteúdo (o que vemos e ouvimos), no emprego (quem escreve, reporta e produz o conteúdo) e, acima de tudo, na propriedade (quem detém as empresas que decidem o conteúdo), para que as histórias de todos os americanos possam ser contadas, assim como todas as vozes ouvidas" (s/d: 5 ).

De acordo com a mesma entidade, a forma como o público vê vários assuntos, quer tenha consciência disso ou não, está diretamente relacionada com a cobertura que os media fazem sobre os mesmos. Por sua vez, esta cobertura depende de quem trabalha nos media (repórteres, produtores, etc., que escolhem os ângulos para contar as histórias). Mantendo a sucessão, a escolha de quem trabalha nos media liga-se a quem detém os media. Finalmente, a posse dos media está relacionada com políticas que determinam quem tem licença para operar e quem não tem.

Neste sentido, a organização encontra desvantagens, associadas à falta de diversidade nos media: se uma empresa puder comprar uma larga variedade de media para atingir um público ou comunidade, vai disponibilizar apenas uma voz, ou seja, a diversidade de pontos de vista é afetada; além disso, se não houver representantes de minorias, mulheres e pessoas mais velhas ou com deficiências, empregados na produção de notícias, em diversos níveis de gestão, não haverá quem possa falar com alguma autoridade sobre a sua condição e sobre pessoas de algumas comunidades, o que leva a uma menor cobertura de assuntos que seriam importantes para esses eleitorados; por fim, se não houver integração local na gestão das notícias que chegam a cada localidade, temas importantes para as comunidades locais podem ser ignorados, o que significa que o interesse do público não está a ser tido em conta.

\section{Enquadramento legal ligado à diversidade nos EUA e Reino Unido}

A existência de diversidade no sistema de media de um país está diretamente relacionada com a adequação das leis em vigor para o setor e com o facto de estas serem cumpridas ou não. Como já foi referido, a propriedade dos media pode ser um fator condicionante da diversidade mediática numa região. É por isso que, nos EUA, restringir a concentração dos media é a missão central da FCC (Federal Communications Commission), a agência federal que regula as comunicações entre estados e internacionais. Para evitar a concentração, é função da FCC regular a propriedade dos media, estabelecendo quantas estações uma empresa pode deter em cada mercado, assim como limites para a propriedade cruzada de diferentes setores, como estações televisivas e jornais diários. Neste sentido, desde o Ato de Comunicações de 1934, a FCC deveria promover a intervenção regional nos media e garantir que, por exemplo, representantes de minorias e mulheres pudessem ser 
proprietários, afirmando, assim, uma democracia em que todas as comunidades têm voz no espaço público.

No entanto, de acordo com a Leadership Conference Education Fund, o Ato de Comunicações de 1996 desregulou a posse de rádios nacionais e tornou mais fácil deter canais de televisão nacionais. A partir daí, o confronto entre as preocupações com a diversidade e os interesses económicos de grandes empresas tem sido constante ao longo dos anos, devido à ameaça realizada aos princípios iniciais. Por exemplo, a FCC pretendeu eliminar os limites à propriedade cruzada que, em vigor, proíbem que a mesma empresa detenha uma estação de rádio ou televisão e o jornal diário mais vendido, na mesma área, entre outras restrições.

No Reino Unido, por sua vez, existe o Ofcom (Office of Communications) para regular as comunicações. É a entidade pública responsável por proteger os consumidores dos serviços de comunicação contra práticas ilegais e por assegurar a existência de condições para uma concorrência justa entre operadores. Uma das preocupações do regulador é garantir que existe igualdade de oportunidades no acesso ao emprego nos media. Tendo em vista o objetivo referido, publicou um conjunto de indicações jurídicas para que os empregadores da indústria da televisão possam aumentar a diversidade e a justiça nas suas contratações, respeitando a lei da igualdade (Ato da Igualdade de 2010) e os direitos humanos: "Thinking outside the box: Supporting the television broadcasting industry to increase diversity".

0 princípio mais importante do referido Ato é, de acordo com o regulador, a obrigação de "tratar todas as pessoas de forma justa e dar-lhes oportunidades iguais para desenvolver o seu potencial" (EHRC/Ofcom, 2015: 6). Na prática, este princípio estabelece que "a seleção de trabalhadores para cargos e papéis deve ser alicerçada no mérito, demonstrado através de critérios e processos, considerados justos e transparentes" (EHRC/Ofcom, 2015: 6). Por outras palavras, é proibida a discriminação baseada em nove características protegidas: idade, deficiência, reatribuição de género, casamento ou união de facto, gravidez e maternidade, raça, religião ou crença, sexo e orientação sexual.

Assim sendo, recrutar uma pessoa devido a ter uma característica especial é geralmente proibido pelo Ato, pelo que é necessário algum cuidado na promoção da diversidade para não infringir a lei, discriminando outras pessoas acidentalmente. Todavia, o Ofcom realça algumas exceções a essa regra: a proteção é permitida quando o facto de a pessoa possuir uma característica especial específica é um requisito aceitável para 0 trabalho, pelo que a escolha passa a ser justificável (podemos estar a falar da necessidade de autenticidade ou realismo em papéis, por exemplo). Para além disso, são permitidas algumas medidas de ação positiva: encorajar pessoas pertencentes a grupos sub-representados ou em desvantagem para que se candidatem a lugares ou ajudá-las a adquirir competências que as capacitem para competir em pé de igualdade com outros candidatos. Por fim, há uma forma de ação positiva possível de utilizar em decisões de recrutamento: quando os candidatos apresentam um mérito semelhante, é legal, em várias circunstâncias, selecionar 0 candidato proveniente de um grupo sub-representado ou considerado em desvantagem (principalmente em caso de deficiência, uma categoria mais protegida pela lei, para a qual a discriminação positiva é legal num maior número de ocasiões). 
Panorama atual: estudos SObRe diversidade nos doIS PAíses

Conforme apresentado na introdução, este artigo é baseado em cinco estudos realizados por entidades dos dois países considerados, que procuraram, a partir de diferentes pontos de vista, avaliar a diversidade mediática dos EUA ou do Reino Unido, propondo estratégias (apresentadas no próximo subtítulo) para tornar os media mais diversos.

No Reino Unido, a emissora pública de rádio e televisão (BBC) procurou quantificar a presença de mulheres, minorias étnicas e de pessoas com deficiência, de raça negra ou incluídas na categoria LGBT (lesbian, gay, bisexual, and transgender) no emprego (incluindo cargos de chefia) e no ecrã (incluindo a atribuição de papéis com destaque). A conclusão principal retirada foi, precisamente, que a composição, quer do emprego, quer das presenças no ecrã, não era representativa da audiência, ou seja, da distribuição da população do país. Para que tal acontecesse, tanto em frente às câmaras como atrás, as percentagens relativas à presença dos grupos referidos deveriam rondar os seguintes números: $50 \%$ de mulheres, $8 \%$ de pessoas com alguma deficiência, 8\% de personagens e trabalhadores LGBT e 15\% de pessoas de cor negra, asiáticas ou de outras minorias étnicas. Todavia, a emissora reconhece que os principais grupos sub-representados nas suas atividades são os portadores de deficiência e as pessoas que se inserem na categoria LGBT (para com as quais não havia, até à data do relatório, qualquer preocupação de inclusão). É, então, no relatório intitulado "Diversity and Inclusion Strategy 2016-2020 - Diversity includes everyone", que a BBC enuncia os objetivos a atingir e as estratégias pensadas para que estes sejam concretizados.

Além da BBC, também a entidade reguladora das comunicações no Reino Unido (Ofcom) considera que "qualquer pessoa que queira tentar ter uma carreira na televisão deve ter uma oportunidade justa e igualitária para o fazer, independentemente do seu contexto de origem" (2015: 5). Todavia, na perspetiva desta entidade, os números mostram que "alguns grupos podem estar a encontrar barreiras para entrar na indústria ou para alcançar progressos depois de entrarem" (2015: 5). A título de exemplo, o Ofcom refere que as mulheres e as minorias étnicas estão sub-representadas em cargos executivos, que o número de pessoas com deficiência a trabalhar nesta indústria é reduzido (comparativamente à proporção que ocupam na população em idade ativa) e que, no ecrã, é pouco provável que os apresentadores sejam mulheres com mais de 55 anos. Além disso, a representação que é feita de alguns grupos já mencionados (minorias étnicas e pessoas com deficiência ou pertencentes à categoria LGBT) nem sempre coincide com a realidade das suas vivências. Tendo em vista 0 aumento da diversidade na indústria britânica de televisão, o Ofcom refere também, no documento já citado "Thinking outside the box: Supporting the television broadcasting industry to increase diversity", quais são as opções legais para tornar a força de trabalho mais diversa e inclusiva.

A realidade americana é igualmente alvo de críticas por parte de estudos relativos a este país. Uma das entidades preocupada com a falta de diversidade nos media americanos é a Leadership Conference Education Fund, organização que luta pela defesa dos direitos humanos e civis dos americanos. No documento intitulado "Media Diversity Matters: A Media Justice Activist Toolkit" critica a atuação da FCC, entidade responsável por regular as comunicações nos EUA, e esclarece 
a forma como esta deveria atuar e o que os cidadãos podem fazer para se oporem à concentração da propriedade dos media, entre outros problemas. Em forma de resposta a possíveis dúvidas dos cidadãos recetores da mensagem sobre o motivo da falta de diversidade, a Leadership Conference Education Fund afirma: "Desde a imprecisa e limitada representação de minorias e mulheres na televisão, até às vozes homogéneas na rádio, o sistema de media do nosso país está a tornar-se cada vez menos diverso (...). Esta situação deve-se à falta desproporcional de mulheres e minorias como repórteres, produtores ou proprietários" (s/d: 5).

Reforçando as visões já referidas, investigadores e estudantes da USC's Annenberg School for Communication and Journalism, em Los Angeles, verificaram que existe uma falta de representação, nomeadamente de mulheres (cerca de 40\%, número que diminui no caso de cargos executivos), indivíduos de raça negra (estão totalmente ausentes em 22\% dos programas analisados) ou personagens LGBT (apenas 2\% do total e quase exclusivamente homens brancos) em programas de entretenimento.

A conclusão está incluída no relatório "Inclusion or Invisibility? Comprehensive Annenberg Report on Diversity in Entertainment" que avalia a inclusão, no ecrã e atrás das câmaras, em filmes de ficção, programas de televisão e séries digitais distribuídas por dez grandes empresas (21 st Century Fox, CBS, Comcast NBC Universal, Sony, The Walt Disney Company, Time Warner, Viacom, Amazon, Hulu, e Netflix) em 2014 ou 2015. A unidade principal de análise foram as personagens com falas, ou com um nome, nos filmes ou no guião original das séries escolhidas. Cada personagem que tivesse intervenção verbal era classificada por vários indicadores: "papel, demografia, domesticidade e hipersexualização" (2016: 3). Atrás das câmaras, 0 sexo de diretores e escritores de cada filme e episódio das séries que constituíam a amostra foi verificado. Foi, também, avaliada a raça/etnia dos diretores de filmes, assim como das pessoas que estavam a dirigir o primeiro episódio da temporada dos programas de televisão ou digitais. Por fim, foi avaliada a composição do sexo de CEO's, membros de equipas executivas e quadros de diretores.

No âmbito deste artigo, destacamos apenas os resultados mais importantes sobre a avaliação das empresas relativamente à diversidade: quatro empresas (The CW Network, The Walt Disney Company, Amazon, Hulu) demonstraram uma prestação forte ao nível da representação feminina no ecrã e atrás das câmaras, embora a Amazon tenha sido a única empresa considerada "plenamente inclusiva" no que toca à presença de mulheres como diretoras. Por outro lado, houve três empresas (Time Warner, 21st Century Fox e CBS) que não foram consideradas "plenamente inclusivas" em nenhum indicador, pelo que têm um longo caminho a percorrer ao nível da implementação de diversidade na sua atividade. Relativamente aos restantes indicadores, todas as empresas precisam de incrementar a diversidade, já que obtiveram resultados médios ou baixos, o que revela, por exemplo, uma presença demasiado reduzida de personagens LGBT ou de etnias minoritárias.

Também o relatório anual "Where We Are on TV", elaborado pela GLAAD (Gay \& Lesbian Alliance Against Defamation), apresenta conclusões relativas à representação de homens e mulheres, diferentes raças e etnias (personagens negras,

1 Para informações mais pormenorizadas sobre as categorias de análise ver notas 3 a 7 na página 21 do relatório. 
latinas, asiáticas), pessoas com deficiências, transexuais e bissexuais em três categorias (broadcast, cable e streaming) nos EUA. Além disso, é avaliado o tipo de programas em que estes grupos são representados e se estão incluídos na programação diurna e naquela cujo idioma falado é o espanhol. Para tal, é considerado o guião original das séries que estão no ar (ou com início confirmado) em horário nobre, entre junho de 2016 e maio de 2017.

Mantendo o padrão seguido até aqui, vamos apresentar alguns resultados mais relevantes para a realidade broadcast e cable. Estes demonstram progresso nos vários indicadores, evidenciando, todavia, a necessidade de mudança para atingir a verdadeira diversidade: das 895 personagens com presença "habitual" previstas nos guiões para a programação do horário nobre das redes de transmissão (broadcast), 43 (4,8\%) eram identificadas como LGBT0 (/esbian, gay, bisexual, transgender and queer); os serviços de cabo (cable) deveriam conter uma maior diversidade racial no que se refere às personagens $L G B T 0$, já que a esmagadora maioria $(72 \%)$ são classificadas como "brancas"; $20 \%$ (180) das personagens "habituais" na programação do horário nobre das redes de transmissão eram negras, sendo esta a percentagem mais elevada desde que a GLAAD começou a compilar dados abrangentes relativos à raça, há doze anos; no entanto, as mulheres negras continuam sub-representadas, já que apenas 69 (38\%) das personagens negras são do sexo feminino; durante este ano, haverá personagens transexuais "habituais" (três em broadcast e seis no cable); o número de personagens lésbicas e bissexuais "habituais" diminuiu comparativamente ao ano anterior, nas duas plataformas, depois de um período "particularmente mortal" para as personagens queer femininas (0 número de personagens passou de 98 para 92); para terminar, a proporção de personagens com uma deficiência, consideradas "habituais" nas redes de transmissão, subiu de $0,9 \%$ para $1,7 \%$, a percentagem mais elevada desde que a GLAAD começou a elaborar estatísticas sobre "deficiência" em 2010.

\section{ESTRATÉGIAS PARA INCREMENTAR A DIVERSIDADE E INCLUSÃO NA TELEVISÃO}

Perante os resultados acima apresentados, passamos a expor as estratégias sugeridas por cada entidade, com o objetivo de incrementar a diversidade televisiva. A BBC traçou, como foi referido, um plano de ação para representar fidedignamente a sua audiência, quer no ecrã (ao nível de vivências ou presença frequente e não estereotipada), quer ao nível dos seus trabalhadores (funcionários e diretores provenientes de diferentes contextos promovem melhores ideias e simplificam a tarefa de estar de acordo com os interesses de uma proporção maior da população, resultando em conteúdo mais interessante), até 2020.

Entre outras medidas, a emissora pública britânica pretende: fazer mais programas que representem as suas audiências, através do desenvolvimento de orientações (em conjunto com várias entidades, em parte constituídas por representantes das minorias-alvo, por exemplo) para que os guiões respeitem os valores e compromissos definidos; investir na contratação de profissionais de diferentes grupos "protegidos", garantindo um conjunto de programas e fundos para financiar o desenvolvimento do seu talento, enquanto já estão a trabalhar; incluir as audiências em processos de decisão, através de novos mecanismos de interação online ou pessoal, o que permitirá chegar a todos os públicos; garantir que as entrevistas de 
trabalho são justas para todos e que os grupos sub-representados não encontram barreiras para conseguir emprego (podendo começar como aprendizes, por exemplo); manter uma base de dados que permita perceber qual o tipo de trabalhadores que constituem a empresa e quais precisam de mais oportunidades para conseguir um emprego (tem o nome de Diamond e o seu o objetivo é aumentar a transparência e medir a verdadeira diversidade nesta indústria); garantir que há diversidade na escolha dos líderes, através de programas de preparação, e que eles próprios irão estar preparados para promover uma cultura de trabalho não discriminatória; verificar se não há barreiras físicas, nomeadamente no que diz respeito aos edifícios e acessibilidades, que impeçam trabalhadores com deficiência de realizar 0 seu trabalho devidamente; desenvolver parcerias que possam garantir aconselhamento sobre diversidade ou intermediar a chegada de trabalhadores de grupos sub-representados a cargos na BBC.

Numa perspetiva diferente, a Leadership Conference Education Fund aconseIha os cidadãos norte-americanos a manterem-se informados sobre os direitos civis e, em primeiro lugar, a prestarem atenção aos media que ouvem e veem, desde 0 jornal local até à televisão ou rádio que chega a todo o país. 0 objetivo, de acordo com a organização, é fazer cada cidadão pensar sobre de que forma os media poderiam servir melhor a sua comunidade. 0 próximo passo para aumentar a diversidade seria, então, cada cidadão expor o seu descontentamento à FCC (Federal Communications Commission), escrever cartas para o jornal local e alertar as pessoas ao seu redor sobre a importância da diversidade nos media. 0 relatório elaborado pela organização inclui um modelo de carta que pode ser utilizado para expressar preocupação sobre a falta de diversidade nos media e incita à discussão sobre 0 tema em fóruns formais e informais, de modo a dar início a mudanças através da mobilização da população ou, neste caso, das várias audiências.

Após avaliar a prestação de várias empresas em separado, o relatório da USC'S Annenberg School for Communication and Journalism, em Los Angeles, refere que não é possível promover a diversidade com medidas esporádicas ou pensadas apenas para um filme, episódio ou contratação. Defende, pelo contrário, que "a inclusão requer um ecossistema no qual diferentes perspetivas têm valor e as histórias representam o mundo em que vivemos" (2016: 17), o que torna necessário "contrariar enviesamentos implícitos e explícitos" (2016: 17). Este objetivo obriga a uma mudança profunda na ação das empresas que deve adotar múltiplas estratégias, já que precisa de solucionar problemas variados: estabelecer objetivos de inclusão transparentes e públicos; reconhecer e alterar pensamentos estereotipados, pensando em exemplos contrários a esse estereótipo, antes de decidir uma contratação ou finalizar um guião; criar verificações e equilíbrios na revisão de qualificações e em decisões sobre a forma de contar histórias, através da implementação de um sistema que promova o processamento cuidadoso para ultrapassar preconceitos cognitivos; elaborar listas de consideração inclusivas para a escolha de escritores e diretores, assegurando que contêm $50 \%$ de mulheres e 38\% de pessoas de raça negra; contrariar o recurso a mitos nos processos de decisão, recorrendo, para tal, a factos ou evidências, especialmente no que diz respeito à prestação financeira de filmes onde os líderes e/ou diretores são mulheres ou outros grupos habitualmente não representados; continuar a monitorizar o progresso, uma vez que a avaliação 
permite não apenas demonstrar onde continua a ser necessário melhorar, mas também perceber onde é que houve conquistas realizadas.

Visando melhorar a diversidade percetível no ecrã, também o relatório elaborado pela GLAAD (Gay \& Lesbian Alliance Against Defamation) inclui sugestões sobre a presença de diferentes personagens nas plataformas analisadas nos EUA. Relativamente ao broadcast, a GLAAD afirma que se trata da plataforma (entre as três estudadas) mais "mortífera" para mulheres lésbicas e bissexuais, com pelo menos doze personagens mortas desde o início de 2016, sem que tenham sido devidamente substituídas por outras. A organização gostaria de ver este tipo de personagens a ter continuidade nas séries, pois, caso contrário, é passada uma mensagem perigosa para o público sobre a sua importância e a diversidade torna-se reduzida. Por outro lado, a GLAAD reconhece algum esforço na inclusão de personagens transexuais, embora reitere que ainda é necessário introduzir personagens transexuais masculinas, já que estas permanecem invisíveis nos principais media. No caso do cable, a organização mantém a observação que fizera no ano anterior, frisando uma vez mais que gostaria de ver maior diversidade na expressão da comunidade LGBTQ: das 142 personagens "habituais" e "recorrentes" esperadas, 72\% (102) são "brancas" (como tinha sido referido no subtítulo referente aos estudos sobre o panorama atual), o que representa um retrocesso comparativamente a 2015 , onde esse valor fora de $71 \%$.

\section{CONCLUSÃo}

Podemos afirmar que, atualmente, as televisões britânica e norte-americana têm graves fragilidades ao nível da representação das audiências no ecrã e atrás das câmaras, o que, vivendo em democracia, constitui um problema. Todavia, é importante realçar um aumento generalizado da preocupação com este aspeto, nomeadamente devido à emergência de estudos, como aqueles que referimos aqui, que denunciam publicamente o que deve ser alterado, facilitando a adaptação das empresas e favorecendo a igualdade de oportunidades entre todos os cidadãos. Desta preocupação resulta um número considerável de estratégias para tornar a indústria televisiva mais inclusiva (expostas no tópico anterior) e a necessidade de verificar que ações são permitidas pela legislação, bem como de perceber se esta é adequada aos objetivos de incrementação da diversidade.

\section{REFERÊNCIAS BIBLIOGRÁFICAS}

BBC (2016). Diversity and Inclusion Strategy 2016-20 Diversity includes everyone. In: http:// downloads.bbc.co.uk/diversity/pdf/diversity-and-inclusion-strategy-2016.pdf (acedido 19/01/2017).

Choueiti, M.; Pieper, K. \& Smith, S. (2016). Inclusion or Invisibility? Comprehensive Annenberg Report on Diversity in Entertainment. Gender Media, Diversity, \& Social Change Initiative Institute for Diversity and Empowerment at Annenberg (IDEA). USC's Annenberg School for Communication and Journalism. In: http://annenberg. usc.edu/pages/ /media/MDSCI/CARDReport\%20FINAL\%2022216.ashx (acedido 19/01/2017).

GLAAD (2016). Where We Are on TV 16-17: GLAAD's annual report on LGBTQ inclusion. In: http://glaad.org/files/WWAT/WWAT_GLAAD_2016-2017.pdf (acedido 19/01/2017). 
Leadership Conference Education Fund. Media Diversity Matters: A Media Justice Activist Toolkit. In: http://www.civilrights.org/action_center/media-diversity/media_justice_activist_toolkit.pdf (acedido 19/01/2017).

Ofcom e EHRC (2015). Thinking outside the box: Supporting the television broadcasting industry to increase diversity. In: https://www.ofcom.org.uk/_data/assets/pdf_file/0030/47496/increasing-diversity.pdf?utm_source=updates\&utm_ medium=email\&utm_campaign=online-diversity-resource (acedido 19/01/2017).

Raquel Lourenço - Bolseira de Iniciação Científica do CIC.Digital (Pólo FCSH/NOVA)

Data de recepção do artigo/ Received for publication: 01.03.2017

Data de aceitação do artigo/ Accepted in revised form: 15.04.2017 